\title{
Stage I Ovarian Cancer AJCC v8
}

National Cancer Institute

\section{Source}

National Cancer Institute. Stage I Ovarian Cancer AJCC v8. NCI Thesaurus. Code C139964.

Stage I includes: T1, N0, M0. T1: Ovarian cancer with tumor limited to ovaries (one or both). NO: No regional lymph node metastasis. M0: No distant metastasis. (AJCC 8th Ed.) 